\title{
Innovation in Strategic Planning at Private Hospital in Central Java District, Indonesia
}

\author{
Nur Hidayah ${ }^{1, *}$, Qurratul Aini², Muh. Amin ${ }^{3}$ \\ ${ }^{1}$ Master of Hospital Administration, Universitas Muhammadiyah Yogyakarta, Indonesia \\ ${ }^{2}$ Master of Hospital Administration, Universitas Muhammadiyah Yogyakarta, Indonesia \\ ${ }^{3}$ Master of Hospital Administration, Universitas Muhammadiyah Yogyakarta, Indonesia \\ *Corresponding author.Email: nurhidayah@umy.ac.id
}

\begin{abstract}
The development of science and technology, especially information and communication technology, has been encouraged the hospital to compete with each other in creating innovation in the various fields using the management information system to achieve the best hospital performance. This study aims to analyze the hospital's strategic plan and the implementation, which focuses on the innovations. This study applied a case study with a descriptive qualitative approach. The data were gathered by analyzing the secondary data in the form of a hospital strategic plan, conducting the interview and Focus Group Discussion (FGD) to investigate its implementation. The participants of Focus Group Discussions (FGD) were 13 participants consisting of top managers and middle managers. The researchers also interviewed the Human Resource Manager and Training and Development Manager. This study revealed that the hospital had conducted innovations in supporting the implementation of hospital strategic plans to implement the management information system. However, some management information systems have been developed, while others are still in the planning process. Additionally, the indicator in assessing the achievement of vision and mission does not exist yet.
\end{abstract}

Keywords: Innovation, strategic planning, implementation, hospital

\section{INTRODUCTION}

Nowadays, the improvement of science in the fields of information and communication technology cannot be denied anymore. Due to the improvement of information and communication technology, the company competes with each other's to create an innovation regarding information and communication technology. The company that can create innovation faster than the competitors will have a new privilege compared with the other company. Thus, the company needs to try some efforts in creating innovation of the company both information technology and communication technology. Innovation is the process of creating a new product or service, new technology, new organization, or the process to improve an existing product or service, an existing technologic process, and an existing organization [1]. In business aspects, innovation plays a significant role in sustaining growth and development and realizing great profit [1]. Thus, innovation plays a significant role in supporting the company in achieving sustainable growth and development and getting the best profit.

The hospital needs innovations in achieving the best performance. Thus, the hospital can achieve the desired goals. The hospital should provide the best service to patients by applying innovation in information and communication technology. Innovation can provide products with better quality and better service for customers [1]. Moreover, the hospital needs to set innovation strategies to achieve the hospital goals by establishing the document, namely, strategic planning. Strategic planning is the standard management tool in a business. It plays a significant role in almost all business fields, both in education, economic, health care, etc. Strategic planning plays a significant role as a critical point of organization success, especially in the hospital. Strategic planning is a series of organizational processes that support the organization in identifying the desired organizational future and developing decision-making guidelines [2].

The hospital's future depends on its capability to determine long-term desired goals and its capability to do several activities to achieve long-term goals. The hospital should set up the plan and strategy as explicitly as possible, and the hospital should make sure whether the plan and strategy can sustain the hospital's existence or not. As already mentioned, strategic planning designed for the development and implementation of the strategies should match the organization's objective [3]. Some healthcare use hospital strategic plans to accomplish hospital accreditation needs, while they have not directed the organization towards the expected future, at least five years later. Besides, the hospital has not implemented information and communication technology optimally. However, due to improved information and communication technology, the disruption of innovation influences the hospital's strategic planning. Thus, it can influence the hospital to change the road map of health service in Indonesia, even in the world. Moreover, the hospital needs to set the hospital strategic plan as useful as possible by implementing the information and communication technology to realize desired goals. Additionally, this research aims to analyze the hospital's strategic plan and the implementation, focusing on the current innovation and future innovation. 


\section{METHOD}

This study applied a case study using a descriptive qualitative approach. The researchers collected the data at one of the private hospitals in Central Java District, Indonesia. The participants of this study included the participants of Focus Group Discussion (FGD) and interview. There were 13 participants of the Focus Group Discussion (FGD) involving top managers and middle managers, while the interview participants were 2 people, including Human Resource Manager and Training and Development Manager. The data were gathered by analyzing the secondary data in hospital strategic planning, conducting the interview, and Focus Group Discussion (FGD) to get a detailed and more in-depth understanding of the hospital strategic planning implementation. Additionally, the data were analyzed using Nvivo 12 plus.

\section{RESULTS AND DISCUSSION}

\subsection{Results}

One private hospital in Central java district, Indonesia, established the hospital strategic plan for 2016-2020 as a preventive, promotive, curative, and rehabilitative approach to achieve the hospital goals set. The hospital vision and mission was described as an effort to realize the hospital goals. The vision was "Becoming an Islamic hospital with comprehensive, excellent and chosen services." Also, the mission consisted of 5 missions, namely; 1) realizing the implementation of Islamic hospital management and services based-sharia principles; 2) realizing comprehensive service; 3) realizing excellent service; 4) becoming the community's choice; and 5) improving enthusiasm, creativity, and quality of all hospital staff to support optimal productivity [4].

The hospital strategic plan has been implemented since 2016. During the implementation process of the hospital strategic plan for 2016-2020, there are some recommendations. The first is related to changing an excellent service, namely orthopedic and Obstetrics and Gynecology (Obsgyn) services. In 2019, there was a strategic plan revision regarding the fulfillment of hospital infrastructure and human resources. That revision occurred because there was a lack of effort in achieving the target set regarding the fulfillment of hospital infrastructure and human resources. The Human Resource Manager explained:

\footnotetext{
"In the process, there was a recommendation regarding excellent services that need to be changed. They are orthopedic and Obstetrics and Gynecology (Obsgyn) services. Besides, in 2019, there was an unclear effort to be achieved regarding the fulfillment of infrastructure and human resources. Human resources' fulfillment was limited to the specialist doctor's recruitments, but an achievement target was not clear. Therefore, the hospital director suggested revising the strategic plan."
}

Besides, in implementing the hospital strategic plan of 2016-2020, both hospital vision and mission have been achieved. Subjectively, the achievement of hospital vision and mission can be presented by several indicators. The first indicator is related to the vision, namely realizing Islamic hospital management and services-based-sharia principles. The hospital successfully achieved the vision. It is presented with the achievement of sharia hospital accreditation on April 17, 2020, from the Indonesian Ulama Council (MUI). The second indicator is related to the second mission: realizing comprehensive service, the third mission: realizing excellent service, and the fourth mission: becoming the community's choice. Hospital successfully obtained a high trust from the public regarding the service provided by the hospital. Even the hospital was quite recognized as one of the healthcare services in Central Java District, Indonesia. It is proven by the hospital's comprehensive accreditation from the Accreditation Committee (KARS) on October 17, 2019. Besides, in actualizing the fifth mission: improving the enthusiasm, creativity, and quality of all hospital staff to support optimal productivity, the hospital carried out several attempts to fulfill educational and human resource needs. In the attempts to fulfill educational needs, the hospital facilitated employees to continue the study by providing scholarships for continuing the Master of Hospital Management and Specialist Doctor Education Program (PPDS), providing tuition fee loans if needed, and providing work dispensation education. The hospital also provided training based on each profession's competence, such as providing skills training for service personnel in the Emergency Room (ER).

Vice Director of Services said:

"The first is the vision, namely sharia-based service. An effort to realize the vision has been carried out. A few months ago, we received a certificate from MUI on April 17, 2020, regarding the sharia suitability towards the hospital service".

"Until now, there are several services that we have a feature." Besides, the services that we feature are entirely recognized in our district. Thus, the core service of our hospital become one of the public choices".

Vice General Director of Finance added:

"Besides Obsgyn services, we are in the process of developing eye services, but there are regulatory constraints such as regarding Organizing Board of Health Social Security (BPJS) and others."

Commonly, the hospital vision and mission based on the strategic plan of 2016 - 2020 has been achieved. However, objectively, the hospital does not develop indicators to assess the hospital's vision and mission. Thus, the hospital is difficult to evaluate the achievement level of the hospital's vision and mission. Also, the hospital's vision and mission will be measurable if there are indicators instruments.

\section{Vice Director of Service:}

"Objectively, until now, there has been no tool used to measure the achievement of vision and mission that have been specified in the strategic plan." One of our weaknesses is that we do not have the data as an indicator to measure the achievement of vision and mission." 


\section{Vice General Director of Finance added:}

"So, maybe, it will be more measurable if later it can be balanced with other measurement instruments."

Nevertheless, the hospital has carried out several attempts to realize programs arranged in the hospital strategic plan for $2016-2020$ by providing fulfillment of service needs such as facilitating specialist doctor education, facilitating eye care, hemodialysis care, and tuberculosis care. Besides, the hospital has carried out an effort regarding human resource fulfillment. The hospital provided training related to each profession's competence by providing skills training for the emergency department's service workforce.

The Human Resource Manager explained:

"We facilitated a specialist doctor to continue the study as an effort to fulfill the service need in units." Then, regarding the human resource skills, the hospital carried out the fulfillment of service workforce in the emergency department as an effort to improve doctor and nurse competence".

Vice General Director of Finance added:

"Then, an additional service, namely eye care and hemodialysis care, also have been realized." Besides, Tuberculosis also has been realized regarding the strategic plan".

In practice, during the implementation of the hospital strategic plan for the period 2016 - 2020, the hospital implemented management information systems in supporting the hospital in providing health care for the patient. The hospital used several management information systems, including the financial information system, information system of employee and hospital performance, registration information system, payment information system, medical records information system, human resource information system, and patient care information system.

Financial Information System. The financial information system used by the hospital has not been integrated with technology because of several reasons. First, the hospital accounting system has not been used optimally because the mentoring deadline from related vendors has expired during the system development process. Second, in making financial reports, the hospital was still made a report manually, which used Microsoft Excel. Third, the hospital has not cooperated with related banks regarding patient payment transactions using a bank account. Thus, when a patient wants to make a payment transaction by transfer, the finance department should carry out the manual cross-chek.

Information system of employee and hospital performance. The performance information system is divided into the information system of employee performance and hospital performance system. First is the information system for employee performance. In practice, employee performance has not been integrated with technology, which still used manual methods. The hospital used paper forms to assess employee performance because no system was integrated with the staffing system. Besides, the hospital also used logbooks as media to assess employee performance. In fact, during the implementation of using logbooks as media for assessing employee performance, it did not work effectively because not all employees reported activities related to their performance in each logbook. However, the hospital designed the planning regarding the information system of employee performance, which cooperated with the technologist, for example, by designing an information system of employee performance at the nursing department and hospital back office.

The second is the information system of hospital performance. In assessing the hospital performance, the hospital used the percentage of Bed Occupancy Rate (BOR) to assess each hospital service unit, while the non-service unit assessed by using routine work activities. The hospital also assessed hospital performance regarding the human resource using organizing unit guidelines that integrated with the system, namely the Douglas system. Douglas system has been implemented in one of the in-patient units at the hospital, namely the Ar-Rayyan unit. The Douglas system's implementation used to know the number of human resource needs and competencies needed by human resources. The hospital performance assessment related to quality unit indicators was divided into Revenue Center and NonRevenue Center Unit. Besides, the hospital has not adopted a Balanced Scorecard as a method to assess hospital performance based on four perspectives, including financial, customer, business internal, and learning and growth.

Registration information system. Nowadays, the hospital's registration information system cannot be served online yet but only can be served using patient card and registration by telephone or WhatsApp. The online information system cannot be used because it is still in the trial process. The hospital had carried out the system trial towards the hospital employee before launching the system to test how efficient the system was.

Payment information system. The hospital payment information system is divided based on the hospital's employee status salary to a permanent employee, including basic salary, functional allowance, performance allowance, health insurance allowance, employment agency allowance, and incentive. Indeed, the permanent employee who worked at one of the Revenue Center Unit would like to get direct incentives regarding the best performance in providing health care for the patient. Simultaneously, the salary of a contract employee is determined using a formula based on employee tenure. The hospital payment information system regarding medical staff was divided based on the medical staff who worked at the in-patient and out-patient unit. The payment system of medical staff who worked at the in-patient unit used the INA-CBG (Indonesia Cace Base Groups) system, while medical staff who worked at out-patient used the FFS (Fee for Service) system.

Medical records information system. The hospital medical records information system is still being developed, which cooperates with technologists.

Human resource information system. The hospital's human resource system is still used as a manual method. In inputting the data regarding staffing data, the hospital input the data one by one using Microsoft Excel. However, currently, the 
hospital has cooperated with technologists in designing the human resource information system. Therefore, it can help the hospital to process staffing data efficiently.

Patient care system. The last management information system of the hospital is the patient care system. The patient care system has been integrated with technology, but it is not integrated because the accounting system has not been integrated with the Billing System. Besides, the hospital also has a system integrated with health insurance; thus, it can make the hospital easier in delivering health care for the patient.

\subsection{Discussion}

The hospital strategic plan is a set of strategies that the hospital can be used as the guidelines in managing and developing the hospital; thus, it can support the hospital to achieve the desired goals. Besides, a strategic plan combines futuristic intelligence, objective analysis, and subjective evaluation of values, goals, and priorities to map a future direction and courses of action to ensure an organization's vitality, effectiveness, and ability to add public value [5]. In designing the hospital strategic plan, the hospital needs to consider several things: analyzing the hospital's main problems, determining the hospital goals, analyzing the opportunity, and determining the strategies to achieve the desired goals. As previously mentioned, a strategic plan can be categorized as a tool that contributes to organizational performance and strategy development in formulating the main organizational problems, setting the organization's objective, analyzing alternatives, and choosing the strategy [6]. Moreover, by considering those several things, the hospital can use the strategic plan to measure the hospital performance and know hospital development based on the target achievements established annually.

The hospital needs to set the hospital strategic plan by determining the appropriate strategies to achieve the hospital's long-term success goals. Strategic planning provides strategy implementation as the development guidelines for the company's long-term success [7]. Therefore, creating strategic planning can help the hospital determine how the hospital can pass through for the next few years, how the hospital can achieve its goals, and how hospitals can know how to achieve the goals.

Due to improved communication and information technology, the hospital can carry out the innovation regarding the use of both communication and information technology in implementing the hospital strategic plan. Nowadays, the hospital as a health care organization begins to find out and introduce innovation regarding the implementation of information technology, aiming to provide the best service and improve staff productivity and process efficiency [8]. However, during the implementation of information technology, the hospital should face various challenges and issues. Also, due to the increasing role of technology in the health care organization, especially in the hospital, the technologist and hospital stakeholder face several problems that can hinder the implementation of technology in supporting the hospital performance [9].
During the Coronavirus disease 2019 (COVID-19), some changes occurred regarding economic, health, political, education, technology, etc. Therefore, the hospital needs to adjust the new strategies in designing strategic planning by considering the policy regarding the Coronavirus disease 2019 (COVID-19). The Coronavirus disease 2019 (COVID19 ) is the main trigger towards the accelerated adoption of advances in information technology for health services. In New York City (NYC), Health and Hospitals prioritize to advance the information technology system in five categories namely improving staff efficiency, establishing clinical standards, informatics, improving patient experience, and bridging information systems. Collectively, the innovations not only helped NYC Health + Hospitals address one of the greatest health crises in history but also positioned organizations to be able to use corporate information technology in the new and innovative ways in the period following the COVID-19 pandemic [10]. Information technology plays an essential role in the hospital, responding to the Coronavirus disease (COVID-19). It is based on China's practical experience, presenting that health information technology has been instrumental in the fight against COVID-19. The hospital needs the internet because it provides online consultation to society and medical personnel due to anxiety and depression due to the increasing number of confirmed cases and deaths due to COVID-19. Besides, online consultation services using the internet are also in great demand [11].

\section{CONCLUSION}

The implementation of the strategic plan of one of the private hospitals in Central Java District, Indonesia, for the period 2016 - 2020 has been conducted. Based on the hospital vision and mission set out in the strategic plan for 2016 2020, the overall hospital vision and mission were achieved entirely. It can be seen from the achievements that have been achieved by the hospital, such as; the achievement of accreditation as sharia hospital on April 17, 2020, the achievement of comprehensive accreditation from the hospital accreditation committee (KARS) on October 17, 2019. The hospital has also carried out several attempts regarding fulfilling educational and human resource needs in realizing the hospital mission. However, implementing the hospital strategic plan for 2016 - 2020 has not been appropriately evaluated because the performance assessment indicator has not been determined.

During the implementation of the hospital strategic plan for 2016 - 2020, the hospital implemented a hospital management system due to communication and information technology, consisting of 8 management information systems. There were financial information systems, information systems of employee and hospital performance, registration information system, payment information system, medical records information system, human resource information system, and patient care information system. In practice, the hospital had implemented innovations related to using the hospital management information system integrated with technology. However, some management information systems were integrated with technology from those 
management information systems, and some of those management information systems were still in the planning stage.

Nowadays, the hospital is preparing to establish the hospital strategic plan for the period $2021-2026$. The hospital needs to create a performance assessment indicator to make the hospital more straightforward to evaluate strategic planning performance. Besides, during the COVID-19 pandemic, several significant changes are related to the hospital's activities, from February 2020 until an unspecified amount. Moreover, the hospital needs to describe the new strategies for dealing with the change during COVID-19 occurred.

\section{AUTHORS' CONTRIBUTIONS}

\section{Author 1: Nur Hidayah}

The first author created the design and concept of the study. Besides, the author also participated in drafting and revising the manuscript. Additionally, the author read and approved the final manuscript.

\section{Author 2: Qurratul Aini}

The second author participated in analysing and interpreting the data and also helped in drafting the manuscript.

\section{Author 3: Muh.Amin}

The third author contributed in collecting the data and searching the references to support the finding of this study.

\section{ACKNOWLEDGMENTS}

The researchers thank all parties involved in realizing this research possible. The first is institutions of research, service and publication (LP3M) University Muhammadiyah Yogyakarta that has facilitated during this research regarding the research, namely "The Innovation in Strategic Planning at Private Hospital in Central Java District, Indonesia." The second is Universitas Muhammadiyah Yogyakarta that has held the International Conference of Sustainability Innovation (ICOSI) 2020. Finally, the Master of Hospital Administration, Universitas Muhammadiyah Yogyakarta, has held the 5th International Conference of Hospital Administration (ICHA) part of the International Conference of Sustainability Innovation (ICOSI) 2020 the researchers in publishing this paper.

\section{REFERENCES}

[1] V. Ramadani and S. Gerguri, "Innovations: principles and strategies: Innovations: Principles and Strategies," Strat. Change, vol. 20, no. 3-4, pp. 101-110, May 2011, doi: $10.1002 /$ jsc. 888 .

[2] S. Saleh, A. Kaissi, A. Semaan, and N. M. Natafgi, "Strategic planning processes and financial performance among hospitals in Lebanon: STRATEGIC PLANNING PROCESSES AND FINANCIAL PERFORMANCE," Int J Health Plann Mgmt, vol. 28, no. 1, pp. e34-e45, Jan. 2013, doi: 10.1002/hpm.2128.
[3] R. Lynch, Strategic Management. Pearson UK, 2018.

[4] "RENSTRA RSMT.docx." https://www.scribd.com/document/408605792/RENST RA-RSMT-docx (accessed Nov. 26, 2020).

[5] T. H. Poister, "The Future of Strategic Planning in the Public Sector: Linking Strategic Management and Performance," Public Administration Review, vol. 70, pp. s246-s254, Dec. 2010, doi: 10.1111/j.15406210.2010.02284.x.

[6] H. K. Aggerholm and C. Thomsen, "Strategic Planning," in The International Encyclopedia of Organizational Communication, American Cancer Society, 2017, pp. 112.

[7] R. L. Heath and W. Johansen, The International Encyclopedia of Strategic Communication, 1st ed. Wiley, 2018.

[8] A. K. Jha, D. Doolan, D. Grandt, T. Scott, and D. W. Bates, "The use of health information technology in seven nations," International Journal of Medical Informatics, vol. 77, no. 12, pp. 848-854, Dec. 2008, doi: 10.1016/j.ijmedinf.2008.06.007.

[9] M. Jaana, H. Tamim, G. Paré, and M. Teitelbaum, "Key IT management issues in hospitals: Results of a Delphi study in Canada," International Journal of Medical Informatics, vol. 80, no. 12, pp. 828-840, Dec. 2011, doi: 10.1016/j.ijmedinf.2011.07.004.

[10] R. J. Salway, D. Silvestri, E. K. Wei, and M. Bouton, "Using Information Technology To Improve COVID-19 Care At New York City Health + Hospitals: Commentary describes New York City Health + Hospitals use of innovative technological solutions to respond to the COVID-19 pandemic.," Health Affairs, vol. 39, no. 9, pp. 1601-1604, Sep. 2020, doi: 10.1377/hlthaff.2020.00930.

[11] Q. Ye, J. Zhou, and H. Wu, "Using Information Technology to Manage the COVID-19 Pandemic: Development of a Technical Framework Based on Practical Experience in China (Preprint)," JMIR Medical Informatics, preprint, Apr. 2020. doi: 10.2196/preprints. 19515 . 